\title{
MENYINGKAP PERADABAN ISLAM KONTEMPORER DI ANAK BENUA INDIA
}

\author{
Mohammad Asrori \\ Fakultas Tarbiyah UIN Maulana Malik Ibrahim Malang. Jalan Gajayana 50. Malang 65144 Telp. 0341- \\ 551354, 08165461026. e-mail: Asroobadali @ yahoo.com
}

\begin{abstract}
Civilization and culture in the arm of the continent of India had undergone the rise and fall since the colonialism era until the independence day. It can be illustrated by the domination of political map which had existed since the arrival of foreign nation, especially England until they got their indepence. The condition of Indian society at that time was full of contradiction, religion coflicts, quarrelling, robbery, various race, certain group interest dominating, and etc. From this condition, it born many great islamic political figures like Syeh Ahmad Sirhindi, Shah Waliyullah and the next generation, Sayyid Ahmad Khan and the next generation, Indian Moslem League. Which finally made India and Pakistan Independence (1947 M) and Bangladesh's (1971M). Next, these three countries, which are the same in term of historical country have also various dynamic and sophisticated improvement of Islam.
\end{abstract}

Key words: civilization/culture, politics, thought, moslems 


\section{Pendahuluan}

Sejarah perkembangan ilmu pengetahuan ternyata memiliki dinamika dalam konteks kehidupan peradaban umat manusia. Mereka kadang-kadang dapat menapaki pada tataran struktur wilayah yang paling teratas (al Ashry al Dzahaby at Tamadduny) dalam suatu komunitas tertentu, atau bahkan justru sebaliknya (al Ashy at Taakhuriy at Tamadduny). Sejalan dengan pendapat tersebut, Said Agil Siradj juga pernah menukil dari seorang sosiolog Muslim Ibnu Kholdun yang mengatakan bahwa "Dunia itu berputar-putar sebagaimana halnya roda pedati yang berputar-putar mengitari As-nya” (Siradj, 1997: 6).

Sebagai reaksi dibalik makna dimaksud, pernyataan Ibnu Kholdun ini dapat mengingatkan kembali proses dinamika perkembangan peradaban dalam suatu masyarakat atau bangsa, diantaranya anak benua India yang menjadi obyek pengkajian ini. Berbagai kajian yang sengaja diangkat dalam tulisan ini dapat diperjelas seputar perkembangan politik Inggris di Anak Benua India. Kajiannya meliputi pembaharuan Syah Waliyullah dan penerusnya, pemikiran politik muslim pada masa Kolonial, konflik antara partai kongres Liga Muslimin dan implikasinya, dan terakhir perkembangan Islam mutakhir di India. Bertolak dari fokus pembahasan di atas, penulis ingin menggunakan pendekatan deskriptif-analitik-objektif. Ali Mufrodi menandaskan bahwa, pendekatan penelitian deskriptif merupakan penataan sistematik dari sejumlah gejala universum. Pengklasifikasian gejala-gejala yang hendak diteliti menjadi penting agar dihasilkan diskripsi yang sempurna pada permasalahan tertentu. Selanjutnya, pengertian analitik objektif itu dimaksudkan untuk menganalisa secara cermat, teliti, dan objektif mengenai deskripsi yang dihasilkan dalam bentuk data-data penelitian yang berkaitan dengan fokus permasalahannya. Jadi, penggunaan pendekatan tersebut, merupakan alat yang dibuat untuk merefleksikan subtansi analisa pendeskripsian secara objektif pada penulisan ini.

\section{Pembahasan}

\section{Sekilas Perkembangan Politik Inggris di Anak Benua India}

Bertolak dari konteks historisitas India, nama India bermula dari ejaan 
orang barat. Hind diambil dari sebuah nama sungai Shindu yang merupakan satu di antara sungai-sungai yang besar di benua India yang sekarang ini pemerintah di sana berusaha hendak mengembalikannya kepada namanya yang asli yaitu Bharat. Oleh sebab itu disebutlah dia Sind, dan Sind itulah telah menjadi nama daerah tempat kedudukan pusat negara Pakistan sekarang ini (Hamka, 1981: 116).

Masyarakat India telah memiliki keunikan tersendiri dibandingkan negara-negara lain. Negara ini penuh pertentangan, tidak memiliki kesatuan politik yang nyata, penuh berbagai golongan (kelompok), beragam ras yang tidak bercampur-gaul, terpisah oleh keturunan, bahasa, kebudayaan, dan kepercayaan (Stonddrad, 1996: 202).

Dinamika perkembangan di India bermula dipengaruhi oleh tiga invasi besar yang dapat dijelaskan sebagai berikut: 1) Invasi bangsa Arya, mulai tahun 1500 SM. 2) Invasi agama Islam berkembang mulai tahun 1000 M. sampai 1700 M. 3) Terakhir invasi Inggris mulai kira-kira 1750 M. dan mencapai tingkat penaklukan yang sempurna selama seabad kemudian (Stonddrad, 1996: 204). Selanjutnya, sampai pada tingkat terakhir invasi inilah, Inggris dapat menguasai peta perpolitikan yang sangat berpengaruh di India. Awal mula kedatangan bangsa Inggris di India, peta masyarakat India masih dikuasai oleh bangsa Mongol yang terjadi berkisar pada abad XVI. Bangsa Inggris pada saat itu memiliki hubungan dengan India sebatas dengan hubungan perniagaan yang cukup terkenal dengan sebutan dengan 'The East India Company'. Pemimpin besar Turki Mongol dan para penggantinya melakukan operasi penjaharaan kearah selatan dan menghimpun dalam kesatuan politik yang tidak pernah ada sebelumnya (Stonddrad, 1966: 205).

Sebagai reaksi dari fenomena di atas, kaum Brahmana bergerak dan bangkit, bangun menentang untuk kebangkitan kaum Hindu. Akhirnya, kaum Mongol menjadi lemah. Ketika kerajaan Mongol runtuh pada permulaan abad XVIII, sesungguhnya yang terjadi di India dalam kondisi dan situasi kacau, raja-raja berperang satu sama lain. Raja-raja pemeluk Islam melawan yang Hindu, berperang mengenai soal agama, soal politik, dan kadang-kadang hanya karena mereka ingin merampok satu sama lain (Stonddrad, 1996: 217). 
Bangsa Inggris dan bangsa Eropa lainnya sebagaimana halnya Portugis, Belanda, Prancis bergerak untuk menguasai tempat-tempat tertentu dalam kerangka mencari rasa aman terutama pabrik-pabrik mereka. Namun demikian yang paling getol dalam penguasaan daerah-daerah dari sekian bangsa Eropa adalah Inggris. Ia merupakan bangsa yang berhasil menancapkan kakinya dengan kokoh dan memiliki pertahanan di tengah situasi dan kondisi kekacauan di bumi India. Perubahan sikap Inggris ternyata tampak jelas, berangkat dari hubungan yang hanya perniagaan menuju ambisi penguasaan pemerintahan yang kokoh.

Sebagai respon dari bangsa India dalam menghadapi fenomena di atas, mereka mengalami kecemasan yang terjadi dikalangan bangsa India, yang menyebabkan meletusnya pembrontakan berdarah pada tahun $1875 \mathrm{M}$ peristiwa ini juga digambarkan oleh Rasihan Anwar dalam buah karyanya 'Ajaran dan Sejarah Islam Untuk Anda' dengan sebutan 'The Great Indian mutiny', yang memiliki pemahaman tentang serdadu-serdadu Sepoy atau Sepahi di kalangan tentara kompeni Inggris, dan sisa-sisa kaum bangsawan Muslim yang terakhir, yang berkumpul di belakang raja Mongol yang penghabisan di Delhi, menderita kekalahan. Maka dengan demikian kekuasaan Inggris atas India semakin kuat (Anwar, 1962: 210-11).

Kekacauan dan pembrontakan di India dapat dipadamkan dan 'East India Company' dibubarkan. Pada saat inilah kekuasaan India langsung dikomandani oleh kerajaan Inggris yaitu, Queen Victoria yang menobatkan dirinya sebagai Maharani India. Perkembangan selanjutnya perubahan disegala bidang dapat dirasakan diberbagai lapisan yang dapat dijelaskan antara lain sebagai berikut: 1) Stabilitas politik, meskipun masih ada perembesan pengaruh-pengaruh Barat dalam corak yang beraneka ragam, 2) Perbaikan jalan-jalan raja, 3) Rekonstruksi jalan-jalan kereta api, 4) Terusan-terusan dibuka yang mempersatukan India, 5) Selesainya terusan Suez dapat pula mempermudah hubunganya dengan Eropa (Stonddard, 1966: 206).

Kekuasaan Inggris atas India tersebut, menjadikan sebuah pemerintahan yang dinamakan patriarchaal absolute. Kekuasaan yang dikendalikan sang raja, suatu pemerintahan yang dikendalikan oleh beberapa ratus orang yang 
mempunyai keahlian dibidang administrasi negara, dibantu sedikit tentara, yang memerintah sejumlah manusia yang tak terkira jumlahnya, dan tanggung jawab pemerintah terhadap rakyat- tidak lebih dari pemerintahan despot pribumi yang disingkirkan. Namun demikian, pemerintahan berjalan dengan baik, meskipun berbagai kebijakan yang dibuat keputusan harus menuai berbagai kritikan dan kekacauan masa depan India sendiri (Stonddard, 1966: 207).

Sebagai reaksi dari masyarakat India yang merespon benih-benih kekacauan dari hasil kebijakan Inggris, ternyata tampak kedamaian dari generasi dan saling mengenal satu sama lainnya. Mereka melupakan penderitaan-penderitaan yang dirasakan masa lalu, dapat pula melihat berbagai kekurangan bangsa Barat, mampu juga menuangkan berbagai pemikirannya dalam mengenali bernegara sendiri menurut sistem Barat, kemerdekaan, dan kebangsaan. Di samping itu, di antara mereka ada yang tidak puas, sehingga memunculkan berbagai gerakan untuk menentang pemerintahan ala Barat, atau bahkan mereka ada yang sangat radikal dan menuntut kemerdekaan.

Sejalan dengan perkembangan politik Inggris yang sudah menguasai bangsa India pada saat itu, mereka ternyata dapat merespon berbagai tuntutan di mayarakat India, terutama setelah berdirinya sebuah organisasi Konggres Nasional India pada tahun 1885 M. Akhirnya lambat-laun berbagai kebaikan Inggris terutatama persoalan politik dan falsafahnya merupakan sebuah penghargaan yang sangat berharga terhadap bangsa India, sehingga dapat mengantarkan pula kemerdekaannya 15 Agustus 1947 M (Stonddard, 1996: 219). Itulah barangkali, fakta sejarah bahwa berbagai kebaikan bangsa Inggris yang dapat dipersembahkan terhadap bangsa India.

\section{Syah Waliyullah dan Penerusnya: Reformer Bangsa India}

Pada abad ke-18 telah muncul seorang reformer di India bernama Syah Waliyullah. Tokoh besar ini terlihat memiliki kecerdasan yang luar biasa sejak dalam tingkat dasar sekitar umur 5 tahun. Menginjak umur 7 tahun ia telah menghafal al Quran. Tahun demi tahun silih berganti. Tepat menginjak umur 15 tahun, ia sudah menguasai berbagai disiplin ilmu pengetahuan seperti halnya: ilmu hukum, tafsir, hadits, ilmu logika, filsafat, astronomi, kedokteran, matematika dan lain-lain. Sebagai penyeimbang 
dari berbagai ilmu pengetahuan yang didapatkan, beliau juga mendalami pengembangan ruhani melalui latihan-latihan dalam tarekat, sebab orang tuanya juga sebagai pemimpin tarekat lokal yang bernama Naqsyabandiyah (Ensiklopedi, 2000: 185 dan Rahman, 2000: 245). Mengingat berbagai pengalaman dan keilmuaan yang beliau miliki sangat komplek, setidaknya ada beberapa catatan penting dari hasil produk-produk intlektual beliau yang ditawarkan di tengah kehidupan masyarakat yang dapat dijelaskan sebagai berikut: (1) Ia tidak suka praktek-praktek sufi yang sudah tidak becus maupun pandangan-pandangan sufi yang ekstrim (Anwar, 1962: 211); (2) Membrantas taklid buta, beliau berpandangan yang dapat diperbolehkan adalah seseorang mengetahui secara jelas apa yang harus dia ikuti (Ensiklopedi, 2000: 186); (3) Ia berhasil menjembatani jurang pemisah antara kaum fuqaha dan kaum sufi (Ensiklopedi, 2000: 178); (4) Ia juga mampu mendamaikan ajaran wahdatul wujud Ibnu Arabi dengan ajaran wahdat asy syuhud suatu konsep keyakinan dalam tasawuf yang menganggap seolah-olah Tuhan bersatu dengan makhlukNya (Engineer, 2000: 276), yang dipelopori oleh Syekh Ahmad Sir hindi (1564-1624 M), (5) Ia menegaskan dalam bidang al Quran bahwa dalam memahami pesan-pesan al Quran sangat penting mengetahui latar belakang social budaya mayarakat Arab pada masa turunnya al Quran, di samping asbabun an nuzul (sebab-sebab turunnya ayat) (Ensiklopedi, 2000: 185), (6) la berpendapat tentang Hadits adalah merupakan dasar bagi semua cabang ilmu agama, sebab tidak mungkin mengetahui syari'at tanpa adanya riwayat dari Nabi SAW, dan tidak mungkin mengetahui riwayat dari Nabi SAW tanpa mengetahui bagaimana proses riwayat itu sejak dari Nabi SAW (Ensiklopedi, 2000: 199).

Dari sisi lain yang dapat dipertimbangkan juga termasuk hasil dari pemikirannya ialah sejumlah karya ilmiahnya mencapai 100 kitab baik ditemukan secara langsung maupun tidak langsung dipermukaan. Namun demikian yang sudah pasti ditemukan dari berbagai karya Syah Waliyullah di belahan Dunia Islam dapat diperkirakan kira-kira 28 kitab, di antaranya: 1) Fuyud al Haramain (limpahan dua kota suci) 2) Al Fatimah (berkisah tentang bangunan spiritual) 3) Al Hujjat al Baligah (argumentasi yang kuat) 4) Al-Fauz 
al Kabir fi Usul at Tafsir (kemenangan besar dalam Usul Tafsir) dan lain-lain (Ensiklopedi, 2000: 101).

Dari berbagai pemikiran di atas ternyata memiliki implikasi yang luar biasa di tengah kehidupan bangsa India dalam berbagai bidang agama, ekonomi, budaya, politik dan lain-lain. Syah Waliyullah pada saat awal kelahirannya memang dihadapkan pada tuntutan situasi dan kondisi sangat krisis yang dimensional di permukaan. Salah satu diantaranya yang paling menonjol adalah disintegrasi kerajaan Mughal (1707-1857 M). Sedangkan sebab disintegrasi dapat dijelaskan ada tiga hal sebagai berikut:

1. Berbagai gubernur atau wali propinsi setengah merdeka berdiri sendiri hingga kerajaan Mughal menciut jadi terbatas pada sekitar Delhi belaka

2. Kerajaan Hindu bernama Maratha naik di Deccan dan karena perang saudara di kalangan penguasa-penguasa Mughal sendiri maka Muratha yang militan itu dapat meluaskan wilayah serta pengaruhnya.

3. Masuknya Inggris, portugis, Prancis, dan Belanda sebagai pedagang, yang berhasil memperoleh rupa-rupa konsesi dari raja Mughal dan jatuhnya Benggala ke tangan Inggris setelah Clive mengalahkan tentara Mughal di Flassey tahun 1757 M (Anwar, 1962: 210-11).

Selanjutnya, setelah Syah Waliyullah selesai masa perjuangannya beliau diteruskan oleh putranya Syeh Abdul Aziz (1746-1824 M) dan cucunya sendiri Isma'il (1781-1831 M). Bersamaan dengan itu bergabunglah dengan Syah Isma'il gerakan pembaharuan yang dilancarkan oleh Sayyid Ahmad Barelawi (1782-1783 M) (Anwar, 1962). Generasi ke generasi berikutnya adalah Syayyid Ahmad Syahid (1786-1931 M), beliau lahir di Rae Bareli dan wafat terbunuh dalam suatu pertempuran. Sebagai penerus Syah Waliyullah ia pernah juga berguru dan melaksanakan baiat ditangan Syah Abdul Aziz yang berarti sebagai pertanda ia menerima sebagai pemimpin ruhaniyah.

Berbagai pemikiran yang ditawarkan oleh Sayyid Ahmad Syahid tidak jauh berbeda dengan pendahulunya Syah Waliyullah. Ada beberapa pemikiran Sayyid Ahmad Syahid yang dapat dikembangkan dalam masa perjuangannya sebagai berikut:

a. Menentang segala bentuk tahayyul dan mengikuti jalan kebenaran yang 
telah ditunjukkan oleh Nabi Allah.

b. Hanyalah Allah yang wajib disembah secara langsung tanpa perantara dan tanpa upacara yang berlebih-lebihan.

c. Kepada makhluk tidak boleh diberikan sifat-sifat Tuhan.

d. Sunnah yang diterima hanyalah sunnah Nabi dan sunnah yang timbul di zaman khalifah empat.

e. Menghadapi Dar al Harb dengan berperang melawannya atau hijrah dari Dar al Harb menuju Dar al Islam (Jamilah, 1993: 30-40).

\section{Pemikiran Politik Muslim Pada Masa Kolonial}

Bangsa India sangat unik dan beragam, lebih-lebih ditunjang dengan masuknya bangsa asing yang semula hanya berdagang seperti Inggris, Portugis, Prancis, dan Belanda berakhir dengan ambisi ingin menguasai dan dapat mendirikan pemerintah sendiri di tengah kehidupan bangsa India tersebut. Masyarakat India ketika melihat negara dan bangsa yang sangat dicintainya itu diporak-porandakan oleh kaum kolonial dan imperialis Barat, maka mereka (baca: umat Islam dan para pemimpinnya) bersatu dan bersadar diri supaya mendapatkan hak kemerdekaannya.

Kesadaran diri itu terlihat pada beberapa contoh diantaranya, pertama, Syekh Ahmad Sirhindi (1564-1624 M) yang memiliki kekuatan spritual dan penganut tarekat Naqsyabandiyah. Ia pernah konflik secara politis dengan Kaisar Jahangir, akan tetapi tidak pernah ditangkap. Tokoh ini juga pernah mengajukan tuntutan terhadap Kaisar dan dikabulkan sebagaimana penjelasan berikut: (1) Kaisar harus menghapuskan Sjadah-I-Tazmizi atau sujud dihadapannya (2) Semua masjid yang telah dirusak harus dibangun kembali (3) Semua yang melarang penyembelihan sapi harus dihapuskan (4) Qadli, Mufti, dan Pejabat lainnya harus ditunjuk untuk menyebarluaskan Islam (5) Jizyah atau pajak keamana harus dijalankan kembali (6) Semua bid'ah harus dihentikan dan dan diganti dengan ajaran-ajaran syari'at (7) Semua tahanan yang dipenjara karena terlibat konflik harus dibebaskan (Engineer, 2000: 275).

Berbagai poin di atas tampak sekali hanya mengedepankan dalam konteks syari'ah dan tidak mengganggu status quo. Ketika kita melihat secara politis, ada kemungkinan terdapat dampak yang paling besar berpengaruh dalam 
proses dinamika birokrasi pemerintahan, lebih-lebih di tengah masyarakat secara luas.

Kedua, Pemimpin lain adalah Syah Waliyullah (1703-1762 M) dan para pengikutnya; Syah Abdul Aziz, Syah Isma'il, Sayyid Ahmad Barelawi, atau bahkan Syayid Ahmad Syahid (1706-1931 M). Mereka memiliki titik sentral pemikiran visi politik yang sangat menarik yaitu; militansi keagamaan dalam melawan penjajahan Inggris (Barat). Sebagai ilustrasi bahwa ketika terjadi krisis politik dan ekonomi (akibat penjajahan bangsa Barat atas Asia maka peran yang dimainkan tokoh agama ortodoks mengalirkan perubahan yang berarti, karena mereka cenderung memainkan peran politik yang progresif, dan perlu disadari bahwa para penjajah memiliki agama yang berbeda. Jika penjajah memiliki agama yang sama, yakni Islam, tentu tidak akan menimbulkan perlawanan yang sedemikian besar (Engineer, 2000: 275-280).

1. Ketiga, Sayyid Ahmad Khan merupakan salah satu kelompok modernis yang lahir di Delhi tahun $1817 \mathrm{M}$ dan dibesarkan dalam lingkungan keagamaan (Jamilah, tt.: 77). Ia memiliki sikap politik di tengah masyarakat ketika terjadi peristiwa besar atau pembrontakan di India pada tahun $1857 \mathrm{M}$ dan merupakan pemimpin alternatif pada saat itu. Sayyid Ahmad Khan, setidaknya memiliki pemikiran politik yang dapat dijelaskan sebagai berikut:

2. Menyadarkan umat Islam bahwa untuk menjadi kuat mereka harus mau mentransformasikan ilmu dan teknologi Inggris sebanyak-banyaknya dalam banyak hal. Karena dengan kerja sama itulah sehingga rasa kecurigaan di antara keduanya akan hilang dan dia berusaha membujuk Inggris agar mengubah sikap kejamnya terhadap umat Islam (Sudarsono, 1994: 167).

3. Berusaha menghilangkan kecurigaan Inggris terhadap umat Islam dan berusaha meyakinkan Inggris bahwa umat Islam bukanlah pemegang peranan utama dalam pembrontakan $1857 \mathrm{M}$ (Al Bahy, 1984: 5).

4. Ia mengeluarkan dua buah karya yang berjudul: Tarikhi Sarkhasi Bijnaur dan Ashabi Baghwat al Hind (berkisah tentang penjelasan latar belakang terjadinya peristiwa $1857 \mathrm{M}$ ) (Al Bahy, 1984: 13).

5. Umat Islam harus memiliki negara tersendiri dan terlepas dengan umat 
Hindu, karena bersatu negara dengan umat Hindu akan membuat minoritas umat Islam yang rendah kemajuaanya akan lenyap yang mana mayoritas Hindu lebih tinggi kemajuannya. Hal ini pada akhirnya, terkenal dengan sebuah gagasan 'komunalisme' (Nasution, 1993: 80-88).।

Berbagai pemikiran politik Sayyid Ahmad Khan di atas diteruskan oleh para generasi berikutnya yang masuk dalam gerakan Aligharghi (dalam Ensiklopedi Islam, tt,) dijelaskan di antaranya sebagai berikut:

a) Nawab Muhsin al Mulk (1837-1907 M). Ia memiliki pemikiran politik di lingkungan Aligharghi yang merupakan basic pengkaderan di bidang politik. Dari sisi lain, juga dapat membuka hubungan antara Aligharghi dengan para ulama di deoband (memiliki sikap keras terhadap Inggris) karena dua kelompok itu, memiliki pandangan yang berbeda dalam politik maupun keagamaan.

b) Vighar al Mulk (1841-1917 M). Pada awal mulanya, pandangan sikap politik mereka mempertahankan kekuatan politik Inggris demi melestarikan umat Islam India. Kemudian sikap politik beliau berpaling akibat pembatalan tentang pembagian pemilihan oleh Inggris. Ia memandang pemerintah Inggris bukan lagi tempat menyandarkan nasib, malahan harus diusir dari India karena memusuhi umat Islam India.

c) Shalahuddin Khuda Bakhs (tt.). Pandangan politiknya bahwa Islam memberi keluasan bagi umatnya dalam melaksanakan kewajibannya sebagai warga negara. Sebagai warga negara umat Islam dalam menjalankan kuwajiban agama tidak harus mengorbankan kesejahteraan materiilnya. Ia juga menggunakan Aligharghi sebagai benteng pertahanan dalam mensosialisasikan berbagai ide politiknya.

d) Muhammad Sybli Nukmani (1757-1914 M). Ia memiliki pemikiran yang moderat, termasuk di antaranya sikap politik yang dikembangkan. Sebagai sentral pergerakannya dalam memajukan umat Islam India adalah Aligharghi.

\section{Konflik Antara Partai Konggres Liga Muslimin dan Implikasinya}

Pada tahun 1900-an mulai muncul gerakan kemerdekaan. Peristiwa ini, disebabkan oleh instabilitas politik, kelompok-kelompok berkepentingan 
yang beragam, sejumlah partai yang beragam di tengah kehidupan bangsa India. Lebih jauh lagi apabila di analisa secara seksama hal itu disebabkan karena, munculnya berbagai pedagang dari bangsa-bangsa Eropa (sebagaimana halnya Inggris, Portugis, Prancis, maupun Belanda), lebih-lebih Inggris telah mampu mengkontrol seluruh India (British India). Di samping itu ada pula tarik menarik (konflik) yang tidak kalah jauh hebatnya antara komunitas Muslim dan Komunitas Hindu.

Seiring dengan dinamika perpolitikan dan perkembangan di tengah masyarakat maka berdirilah 'liga Muslimin India' pada tahun 1906 M, yang memiliki tujuan sebagai penyalur aspirasi Muslim India. Ketika kita melihat secara riil berbagai perbedaan agama, kultur yang sempat memutuskan suatu konsep Komunalisme, maka para pemimpin liga Muslimin India menuntut kemerdekaan dan negara bagi masyarakat Islam terlepas dari India (Ensiklopedi, 2000: 226).

Usaha keras dan perjuangan tanpa lelah, dan cita-cita yang tiada henti-hentinya ini, maka sebagai implikasinya bahwa pada tahun 1947 M pemerintah Inggris telah memberi kemerdekaan India yang dipimpin oleh kelompok nasionalis, serta Pakistan Barat (kini Pakistan) dan Pakistan Timur (Bangladesh) bagi umat Islam. Terakhir, pada tahun 1971, Pakistan timur telah berhasil membentuk negara Bangladesh sesudah membrontak dengan bantuan India, yang mana sebagai pendiri dan presiden pertama dipegang Syekh Mujibur Rahman dengan model negara sekuler (Tim Ensiklopedi, 2000: 277).

\section{Perkembangan Islam Mutakhir: India, Pakistan dan Bangladesh}

Pada dasarnya tiga negara yang disebutkan merupakan serumpun dalam satu negara apabila kita melihatnya dalam sisi histories. Namun perkembangan selanjutnya ternyata melahirkan kenyataan perkembangan yang berbeda, termasuk perkembangan Islam yang menjadi pokok kajian ini. Upaya dalam memudahkan pembahasan ini, maka kita mengkajinya satu-persatu, sebagai berikut:

Pertama: India mulai zaman kolonial, kemerdekaan dan sekarangsesungguhnya memiliki agama Islam yang minoritas. Sedangkan yang mayoritas 
agama Hindu, yang tersisa agama Budha dan lain-lain. Selanjutnya, di tengah arus gelombang yang tidak menentu, pemahaman terhadap Islam maupun umat Islam sekalipun secara ringkas dapat terpolarisasi dalam dua kategori: 1) Tradisionalis, termasuk di antarnya, Deoband, Nadwatul Ulama, Jami'ah Ulama'e Hind. 2) Modernis, yang termasuk di antaranya, Alighar. Tahapan demi tahapan yang terjadi perkembangan Islam di India tidak dapat dilepaspisahkan dari produk-produk yang dikembangkan oleh berbagai institusi yang termaktub di atas. Sebagai bukti kongkritnya kemunculan yang paling mutakhir dapat dijelaskan kelompok Islam tradisional, modernis, dan moderat.

Kedua, Pakistan (Republik Islam Pakistan) yang memiliki ibu kota Islamabad memiliki penduduk: 126.406 .6000 jiwa (1991) dan yang memeluk agama Islam (97\%). Selanjutnya, melihat sekilas tentang perkembangan Islam di Pakistan, sesungguhnya sudah ada terlihat pada tahun 1993 M yang disuarakan oleh gerakan Perkumpulan Mahasiswa Muslim India di Inggris. Sedangkan perkembangan mutakhir Islam yang muncul di Pakistan setelah pasca kemerdekaan, yaitu berusaha untuk mencoba menerapkan konsep Islam tentang sebuah negara. Persoalan inilah yang pada akhirnya menjadikan bahan polemik para tokoh, dan cendekiawan Muslim untuk meneliti dan mengkajinya, seperti halnya, Rancangan Undang-Undang Negara dalam Islam dan lain-lain (Ensiklopedi, 2000: 71-72). Namun demikian, perlu digarisbawahi bahwa Pakistan juga sebagai tempat persemaian para intelektual Muslim dalam mengkaji ilmu-ilmu Islam dan lainnya. Sebagai bukti kongritnya, berbagai madrasah, pengkajiaan agama telah didirikan pada masa Mahmud Gaznawi (971-1030 M) dan berikutnya ada berbagai Perguruan Tinggi Islam yang didirikan sebagai upaya mendukung perkembangan Islam Mutakhir, terutama dalam kajian Islam dan Filsafat. Berbagai Perguruan Tinggi itu dapat dijelaskan sebagai berikut: 1) Yayasan Ilmu Pengetahuan Pakistan 2) Akademi Ilmu-Ilmu Pengetahuan Pakistan 3) Pakistan Philosophical Congress 4) International Philosophical Congress 4) International Islamic Philosophical Association 5) International Iqbal Forum, Lahore 6) Academic Center, Lahore 7) West Pakistan Urdu Academy, Lahore dan lain-lain. Dari hasil yang dikembangkan melalui berbagai Perguruan Tinggi Islam tersebut dapat pula melahirkan para tokoh 
intlektual berkaliber Internasional yang dapat dijelaskan sebagaimana berikut: (1) Muhammad Iqbal 91873-1938 M) (2) Abu 'Ala al Maududi (1903-1979 M) (3) M.M. Syarif (1893-1965 M) (4) Fazlur Rahman dan lain-lain ( Ensiklopedi, 2000: 71-74).

Ketiga, Bangladesh (Republik Rakyat Bangladesh) ibu kota Dacca, penduduk: 108760000 (1991), agama Islam (87\%). Perkembangan Islam dapat dilihat berangkat dari didirikannya puluhan ribu madrasah Ibtidaiyah dan tsanawiyah dan berbagai universitas Islam, di antaranya; Universitas Muslim Jahangirnagar. Dari sisi lain, ada proses Islamisasi secara intensif melalui da'wah, pengajian di Masjid, sekolah di madrasah. Presiden pertama Syekh Mujibur Rahman yang melaksanakan kendali dengan model pemerintahan sekuler (1977), setelah itu banyak pergantian presiden yang terlalu cepat. Selanjutnya gambaran terakhir Islam di Bangladesh, mayoritas bermadzhab Sunni yang tersisa Syi'ah Isma'iliyah (Agha Khani), tidak ada sistim peradilan formal, tetapi para Mullah di daerah boleh bertindak secara informal sebagai qadhi dalam hukum Islam. Kebebasan di negara itu terjamin dan mereka berkomitmen menentang misionaris Kristen (Tim Ensiklopedi, 2000: 225-7).

\section{Simpulan}

Berbagai uraian yang dijelaskan di atas, dapat disimpulkan sebagaimana berikut:

1. Dinamika perkembangan politik Inggris di anak Benua India, dimulai dari kondisi masyarakat yang penuh pertentangan, konflik agama, saling bermusuhan, perampokan, ras-ras yang beragram, kepentingan kelompok yang mengental, kedatangan bangsa Inggris ke India, proses politik yang dikembangkan sampai respon masyarakat India terhadap Inggris. Akhirnya sampai Inggris meletakkan kedaulatannya kepada India pada tahun 1947 M.

2. Kajian pembaharuan dimulai dari pemikiran Syah Waliyullah dan para penerusnya sampai Sayyid Ahmad Syahid (1804-1931 M). Mereka mensosialisasikan pemikirannya dan gerakannya di tengah kehidupan masyarakat India.

3. Mengungkapkan peta pemikiran politik umat Islam dalam menghadapi tuntutan situasi dan kondisi India di bawah cenkreman bangsa asing. Hal 
ini sebagaimana dilakukan oleh Syekh Ahmad Sirhindi, Syah Waliyullah dan penerusnya atau bahkan Sayyid Ahmad Khan dan penerusnya, yang menciptakan aktor-aktor politik di lingkungan Algharghi.

4. Implikasi Liga Muslimin India muncul sebagai sebuah wadah aspirasi umat Islam India membuahkan hasil kemerdekaan India dan Pakistan pada tahun 1947 M berikut, Bangladesh pada tahun $1971 \mathrm{M}$.

5. Dalam konteks historis India, Pakistan dan Bangladesh, merupakan negara serumpun.

\section{Daftar Pustaka}

Al Bahy, Muhammad, 1986. Pemikiran Islam Modren . Jakarta: Pustaka Panjimas. Anwar, Rasihan. 1979. Ajaran dan Sejarah Islam Untuk Anda. Jakarta:PT. Dunia Pustaka Jaya.

Engineer, Asghar Ali. 2000. Islam dan Teologi Pembebasan. Yogjakarta: Pustaka Pelajar Ofset.

Hamka. 1981. Sejarah Umat Islam III. Jakarta: Bulan Bintang.

Jamilah, Maryam.1993. Para Mujahid Agung. Bandung: Mizan.

Jamilah, Maryam, tt. Islam dan Modernisme. Terjemahan oleh A Jainuri dkk. Surabaya: Usaha Nasional.

Jamilah, Maryam, tt. Islam dan Orientalisme : Sebuah Kajian Analitik. Jakarta: PT. Raja Grafindo Persada. Mufrodi, Ali. 1998. Metode Penelitian Sejarah dan Kebudayaan dalam Makalah: Metode Penelitian Sejarah. Surabaya: Tp.

Nasution, Harun. 1992. Pembaharuan Dalam Islam: Sejarah Pemikiran dan Gerakan. Jakarta: Bulan Bintang.

Rahman, Fazlur. 2000. Gelombang Perubahan Dalam Islam: Studi tentang Fundamentalisme Islam. Jakarta: Raja Grafindo Persada. 
Rahman, Fazlur. 1993. Metode dan Alternative Neomodernisme Islam. Bandung: Mizan.

Siradj, Said Agil. 1997. Ahlussunnah Wal Jama'ah dan Hak-Hak Azasi Manusia (HAM), dalam Makalah: ASWAJA dan HAM. Malang: Gedung Uthman Mansur.

Stoddard, Lothrop. 1996. Dunia Baru Islam. Jakarta: Tp.

Sudarsono, Munir. 1994. Aliran Modren Dalam Islam. Jakarta: Rineka Cipta.

Tim Ensiklopedi. 2000. Ensiklopedi Islam Juz I, 4, 5. Jakarta: PT. Ichtiar Baru Van Hoeve. 